\title{
Cheny Tomatoes Ameliorate Scopolamine-induced Amnesia in Mice
}

\author{
Won-Hee Choi, Jiyun Ahn, Suna Kim, and Tae-Youl $\mathrm{Ha}^{\dagger}$ \\ Functional Food Technology Research Center, Korea Food Research Institute, Seongnam 463-746, Korea
}

\begin{abstract}
Cheny tomatoes are rich in antioxidants, which may protect against neurodegeneration and consequent memory loss. This study was conducted to investigate the effect of cheny tomatoes on scopolamine-induced amnesia in mice. Male ICR mice (4 weeks old) were maintained for 4 weeks on a diet containing 10 or $20 \%$ tomato powder (TP), and then administered scopolamine (1 mg/kg body weight, i.p.) $45 \mathrm{~min}$ before memory testing. Passive avoidance and Momis water maze testing revealed that scopolamine-induced amnesia was significantly reduced in the TP groups compared to the non TP-received (control) group. Accordingly, acetylcholinesterase activities in the senum and brain of TP groups were lower than those in the control group. These findings suggest that cheny tomatoes may be useful for the prevention of neurodegenerative diseases such as amnesia and Alzheimer's disease.
\end{abstract}

Key words: acetylcholinesterase, cherry tomato, Morris water maze task, passive avoidance task, scopolamine

\section{INTRODUCTION}

Alzheimer's disease (AD) is the most common type of dementia in modern societies. This condition is emerging as one of the greatest social problems due to its economic and social impacts. The main symptom of $\mathrm{AD}$ is memory loss accompanied by degeneration of basal forebrain cortical and cholinergic neurons. Clinical and $(1,2)$ experimental studies $(3,4)$ have shown that the cholinergic system plays an important role in multiple cognitive functions including learning, memory, arousal, and attention. Accordingly, AD is associated with a decrease in choline acetyltransferase (ChAT) activity in the cortex, hippocampus, and amygdala. $\mathrm{AD}$ is also accompanied by a markedly altered distribution of acetylcholinesterase (AchE) in the brain and degeneration of cholinergic neurons in the central nervous system (CNS) (5). According to the cholinergic hypothesis, elevation of acetylcholine (ACh) levels might alleviate symptoms of cognitive deficits in AD patients. This has led to the development of AchE inhibitors for the treatment of $\mathrm{AD}(6)$.

Scopolamine is a classical antagonist of muscarinic ACh receptors. This compound can pass through the brain-blood barrier and block muscarinic receptors throughout the brain, including the hippocampus and cerebral cortex (7). Blockade of cholinergic transmission with scopolamine decreases neuronal excitability and impairs learning and memory (8), especially learning ac- quisition and short-term memory $(1,9)$. Scopolamine-induced learning and memory impairment in experimental animals has been used as a model for screening anti-amnestic drugs.

Many neurodegenerative diseases, including amnesia and $\mathrm{AD}$, are associated with intracellular oxidative stress. Thus, antioxidants might be useful for the prevention of these diseases. Tomatoes contain many kinds of antioxidant compounds, including carotenoids such as lycopene. Numerous studies have shown that, as natural antioxidants, lycopene and other carotenoids are associated with protection against chronic disease such as cardiovascular disease and cancer (10). The antioxidant activity of lycopene is mainly dependent on its ability to scavenge singlet oxygen and peroxyl radicals. Nonoxidative mechanisms are also thought to underlie the ability of lycopene to prevent cancer. These mechanisms include regulation of intercellular gap junction communication, hormonal and immune systems, and xenobiotic metabolism pathways (11-13). Tomato consumption and serum lycopene are associated with a lower risk for several cancers, particularly those of the prostate, gastrointestinal tract, lung, and urinary bladder $(12,13)$. Of the various tomato genotypes, cherry tomatoes have the highest concentration of antioxidants (lycopene, ascorbic acid, and phenols) and highest antioxidant activity (14). However, whether cherry tomatoes have anti-amnestic effects is unclear. In this study, we investigated whether cherry tomatoes could ameliorate scopolamine-induced 
amnesia in mice.

\section{MATERIALS AND METHODS}

\section{Preparation of tomato powder (TP)}

Goodtrae variety cherry tomatoes were purchased from Buyeo, Chungnam, Korea. The tomatoes were washed and finely diced. They were then dried in a freeze-drier and stored at $-20^{\circ} \mathrm{C}$ until further use.

\section{Animals and diets}

Male ICR mice weighing $25 \sim 30 \mathrm{~g}$ and 4 weeks of age were obtained from Bio genomics, Inc. (Korea). Mice were housed, three animals per cage, under a 12-h light-dark cycle (lights on at 7:30 a.m.) and at a constant temperature of $23 \sim 25^{\circ} \mathrm{C}$ and humidity level of $55 \pm 5 \%$. After an adaptation period of a one week, animals were randomly assigned to one of the following four groups: normal group, control group, TP 10 group, or TP 20 group. Both the normal and control group were maintained on a basal diet (AIN 93G), while the TP 10 and TP 20 group received a basal diet supplemented with $10 \%$ and $20 \%$ TP, respectively. The normal, TP 10 , and TP 20 groups also received an i.p. injection of scopolamine $(1 \mathrm{mg} / \mathrm{kg}$ body weight). Each group was maintained on the diet for 4 weeks and given free access to water and food during this time. The composition of each diet is detailed in Table 1. Body weight and food intake were measured weekly, with measurements being performed at the same time every week.

\section{Passive avoidance task}

Passive avoidance tests were carried out in a shuttle chamber (256000 series, TSE Systems, Germany) that

Table 1. Composition of experimental diets

\begin{tabular}{|c|c|c|c|c|}
\hline \multirow{2}{*}{$\begin{array}{l}\text { Ingredient } \\
\text { (g/kg diet) }\end{array}$} & \multicolumn{4}{|c|}{ Scopolamine (1 mg/kg, i.p.) } \\
\hline & Normal & Control & TP $10^{1)}$ & TP $20^{2)}$ \\
\hline Casein & 200 & 200 & 200 & 200 \\
\hline Corn starch & 529.5 & 529.5 & 529.5 & 529.5 \\
\hline Sucrose & 100 & 100 & 72.4 & 44.8 \\
\hline Cellulo & 50 & 50 & 50 & 50 \\
\hline Soybe & 70 & 70 & 70 & 70 \\
\hline $\mathrm{BHT}^{3)}$ & 0.014 & 0.014 & 0.014 & 0.014 \\
\hline Mineral mixture ${ }^{4)}$ & 35 & 35 & 35 & 35 \\
\hline mixture ${ }^{5)}$ & 10 & 10 & 10 & 10 \\
\hline Cysteine & 3 & 3 & 3 & 3 \\
\hline Cholin bitartrate & 2.5 & 2.5 & 2.5 & 2.5 \\
\hline Tomato powder & none & none & 100 & 200 \\
\hline $\mathrm{kcal} / 100 \mathrm{~g}$ diet & 395.8 & 395.8 & 395.9 & 395.9 \\
\hline
\end{tabular}

${ }^{1)} 10 \%$ tomato powder.

2) $20 \%$ tomato powder.

${ }^{3)}$ Dibutylated hydroxytoluene.

${ }^{4)} \mathrm{AIN} 93 \mathrm{G}$ diet-based mineral mixture.

${ }^{5)}$ AIN 93G diet-based vitamin mixture. contained an identical light and dark compartment and that was equipped with a grid floor and shock generator (8). For the acquisition trials, each mouse was placed in the lighted compartment, and the door between compartments was opened $10 \mathrm{~s}$ later. When the mice entered the dark compartment, the door was immediately closed and an electrical foot shock $(0.3 \mathrm{~mA})$ of $3 \mathrm{~s}$ duration was delivered through the stainless steel rods. The latency period before entering the dark compartment was measured. The next day, for induction of amnesia, mice were injected with scopolamine $45 \mathrm{~min}$ before the avoidance trial to induce amnesia. The mouse was again placed in the lighted compartment, and the time until it returned to the dark compartment was recorded as the step-through latency (with a maximum of $300 \mathrm{~s}$ ).

\section{Monis water maze task}

The water maze was a slightly modified version of the Morris water maze (15). The experimental apparatus consisted of circular water tank (diameter, $100 \mathrm{~cm}$; height, $35 \mathrm{~cm}$ ) containing water at $23^{\circ} \mathrm{C}$ to a depth of $15 \mathrm{~cm}$ and rendered opaque by the addition of powdered milk. A platform was positioned inside the tank with its top submerged $2 \mathrm{~cm}$ below the water surface in the target quadrant of the maze. Each mouse was given three trials per day for two consecutive days to find the hidden platform. Once the mouse located the platform, it was placed on the platform for $10 \mathrm{~s}$. If the mouse could not locate the platform within $180 \mathrm{~s}$, then it was lead to the platform by experimenter. On the third day, amnesia was induced with scopolamine, which was injected 45 min prior to the water maze test. In each training trial, the time required to escape onto the hidden platform was recorded.

\section{Measurement of AchE activity}

The mice were decapitated 120 min after injection with scopolamine, and the serum and the brains were collected. AchE activity was measured using the method of Ellman et al. (16) with slight modification. The whole brain was rapidly homogenized in sodium phosphate buffer (0.1 mM, pH 7.4). For assay of AchE activity, the reaction mixture contained sodium phosphate buffer (0.1 mM, pH 8.0) $2.9 \mathrm{~mL}, 0.01 \mathrm{M}$ DTNB $100 \mathrm{~mL}, 0.075$ $\mathrm{M}$ acetylcholine iodide $20 \mu \mathrm{L}$, and $100 \mu \mathrm{L}$ of homogenate. Changes in absorbance at $412 \mathrm{~nm}$ were recorded. Protein concentration was determined by the method of Lowry et al. (17).

\section{Statistics}

Results are expressed as mean \pm standard error. Group comparisons were performed using a one-way analysis of variance with Duncan's multiple tests. $p<0.05$ was 
Table 2. Effect of the 4-week diet on body weight, food intake, and organ weight

\begin{tabular}{lccrr}
\hline \multirow{2}{*}{ Parameter } & \multicolumn{4}{c}{ Scopolamine $(1 \mathrm{mg} / \mathrm{kg}$, i.p. $)$} \\
\cline { 2 - 5 } & Normal & Control & \multicolumn{1}{c}{ TP $10^{1)}$} & TP $20^{2)}$ \\
\hline Initial body weight $(\mathrm{g})$ & $33.48 \pm 1.90^{\mathrm{ns} 3)}$ & $33.48 \pm 1.87^{4)}$ & $33.52 \pm 1.54$ & $33.48 \pm 1.50$ \\
Final body weight $(\mathrm{g})$ & $45.73 \pm 2.79^{\text {ns }}$ & $45.10 \pm 6.08$ & $44.49 \pm 4.08$ & $47.41 \pm 2.66$ \\
Food intake (g/day) & $5.82 \pm 1.24^{\text {ns }}$ & $5.15 \pm 1.23$ & $4.99 \pm 1.35$ & $4.99 \pm 1.07$ \\
\hline Liver weight (g/100 g b.w.) & $4.08 \pm 0.13^{\text {ns3) }}$ & $4.01 \pm 0.13^{4)}$ & $3.68 \pm 0.14$ & $3.55 \pm 0.13$ \\
Kidney weight (g/100 g b.w.) & $1.43 \pm 0.10^{\text {ns }}$ & $1.57 \pm 0.08$ & $1.51 \pm 0.08$ & $1.41 \pm 0.03$ \\
Spleen weight (g/100 g b.w.) & $0.29 \pm 0.03^{\text {ns }}$ & $0.25 \pm 0.02$ & $0.29 \pm 0.01$ & $0.25 \pm 0.02$ \\
Brain weight (g/100 g b.w.) & $0.94 \pm 0.04^{\text {ns }}$ & $1.00 \pm 0.03$ & $1.04 \pm 0.05$ & $0.92 \pm 0.03$ \\
\hline
\end{tabular}

${ }^{1)} 10 \%$ tomato powder. ${ }^{2)} 20 \%$ tomato powder. ${ }^{3)}$ Not significant.

accepted as significant.

\section{RESULTS AND DISCUSSION}

Effect of TP on body weight, food intake, and organ weight

Body weight, food intake, and organ weight were comparable among all four experimental groups (Table 2). This suggests that supplementation of the diet with up to $20 \%$ TP does not influence dietary intake and growth. This also suggests that treatment of mice with scopolamine does not affect body weight and organ weight change.

\section{Effect of TP on passive avoidance}

The passive avoidance task was used to assess the effect of TP on scopolamine-induced amnesia. Step-through latencies on training day did not significantly differ among the four experimental groups (Fig. 1). However, scopolamine injection on test day significantly decreased step-through latency (normal, 252.94 $\pm 29.93 \mathrm{~s}$ vs. control, $32.2 \pm 14.86 \mathrm{~s}, \mathrm{p}<0.001)$. These results are consistent with previous reports that scopolamine $(1 \mathrm{mg} / \mathrm{kg}$ body weight) shortens step-through latency on the passive avoidance task $(17,18)$, a result indicative of impaired memory retention. Scopolamine, a muscarinic antagonist, is known to block cholinergic signaling and induce memory deficits that are similar to those found in senile dementia $(8,17)$. Importantly, analysis of stepthrough latency in TP-receiving mice revealed that TP significantly blocked the scopolamine-induced reduction in step- through latency, with latency in the TP 10 and TP 20 groups being $65 \%$ and $68 \%$ of that in the normal (vehicle-treated) group, respectively. Step-through latency did not significantly differ between the TP groups, though latency was slightly higher in the TP 20 group $(173.62 \pm 42.67 \mathrm{~s})$ than in the TP 10 group (159.99 $\pm 44.45 \mathrm{~s})$.

\section{Effect of TP on Monis water maze perfomance}

The effect of TP on spatial learning ability was inves-

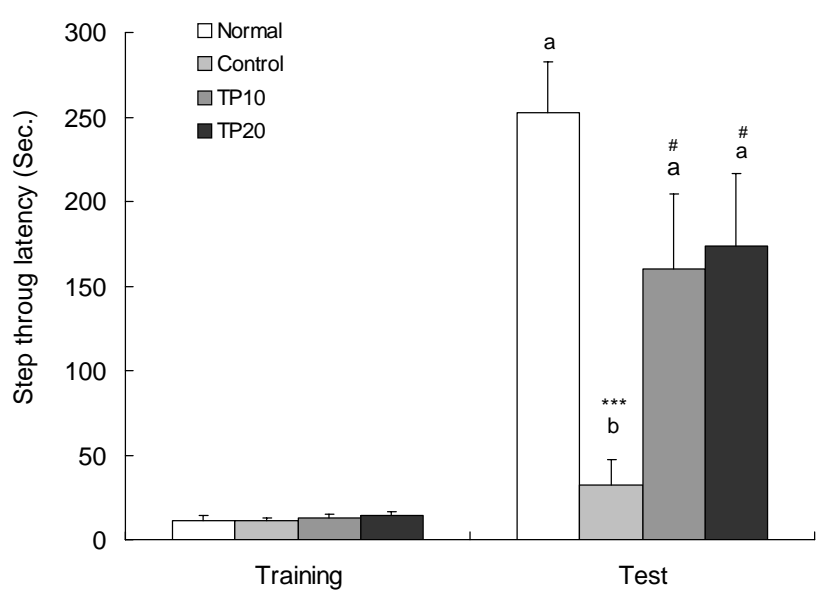

Fig. 1. Effect of TP on scopolamine-induced impairment in passive avoidance. One day after passive avoidance training, mice were tested for avoidance of the dark compartment by measuring step-through latency. A subset of animals received scopolamine $(1 \mathrm{mg} / \mathrm{kg}$ body weight, i.p) $45 \mathrm{~min}$ prior to avoidance testing. ${ }^{* * *} \mathrm{p}<0.001$ vs. normal and ${ }^{\#} \mathrm{p}<0.05$ vs. control ( $n=12$ per group).

tigated using the Morris water maze task. The time taken to find a platform in the water maze (i.e., the escape latency) was used to assess spatial learning (19). As shown in Fig. 2, escape latency was over two times greater in scopolamine-injected control mice than in their vehicle-treated counterparts (control, 87.21 $\pm 13.46 \mathrm{~s}$ vs. normal, $31.42 \pm 10.07 \mathrm{~s}, \mathrm{p}<0.01)$. This prolonged escape time, which is indicative of impaired memory retention, was not observed in TP-receiving animals $(33.27 \pm 8.87$ $\mathrm{s}$ for TP 10 and $44.43 \pm 12.36 \mathrm{~s}$ for TP 20).

\section{Effect of TP on AchE activity}

AchE, which is found at neuromuscular junctions and cholinergic synapses in the CNS, catalyzes the degradation of $\mathrm{ACh}$ into choline and acetate. AchE inhibition is known to antagonize scopolamine-induced amnesia in experimental animals. Analysis of the AchE activity in scopolamine-treated animals revealed that both serum and brain AchE activity were significantly higher in this group than that in the normal (vehicle-treated) group 


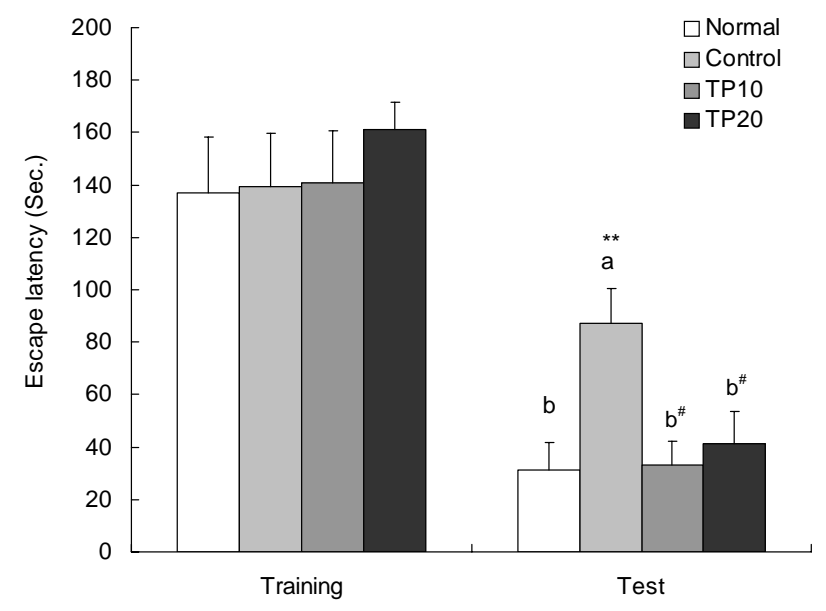

Fig. 2. Effect of TP on scopolamine-induced impairment in Morris water maze task performance. Following two consecutive days training, mice were tested for spatial memory of the platform by determining escape latency. A subset of mice received scopolamine $(1 \mathrm{mg} / \mathrm{kg}$ body weight, i.p) $45 \mathrm{~min}$ prior to testing. ${ }^{*} \mathrm{p}<0.01$ vs. normal and ${ }^{\#} \mathrm{p}<0.05$ vs. control $(\mathrm{n}=$ 12 per group).

(Fig. 3). This result is in agreement with other reports $(20,21)$ that scopolamine blocks cholinergic neurotransmission and increases AchE activity. In accord with its ability to block scopolamine-induced impairments in learning and memory, TP blocked scopolamine-induced increases in brain and serum AchE activity. AchE activity did not significantly differ between the TP groups. These results are encouraging, as inactivation of AchE is considered to be the most successful approach for $A D$ treatment. Many researchers have tried to increase ACh levels in synaptic regions using AchE inhibitors such as tacrine, though some of these drugs are associated with adverse effects $(22,23)$.

Tomatoes, including cherry tomatoes, contain many kinds of carotenoids, such as lycopene and beta carotene, that have potent antioxidant activity and lower the formation of reactive oxygen species (24-27). Intracellular oxidative stress has been implicated in many neurodegenerative diseases such as senile dementia and $\mathrm{AD}$, and antioxidants might be useful for the prevention of these diseases. Accordingly, we have previously shown that, in mice, scopolamine-induced memory dysfunction is ameliorated by seaminol glucosides, a type of antioxidant compounds found in sesame seed (28). Taken together, the current findings suggest that cherry tomatoes are useful for the prevention of amnesia and other neurodegenerative diseases. The protective effect of cherry tomatoes may be mediated by antioxidant activity and/or AchE inhibitory activity. Further studies will be necessary to clarify the mechanism of action.
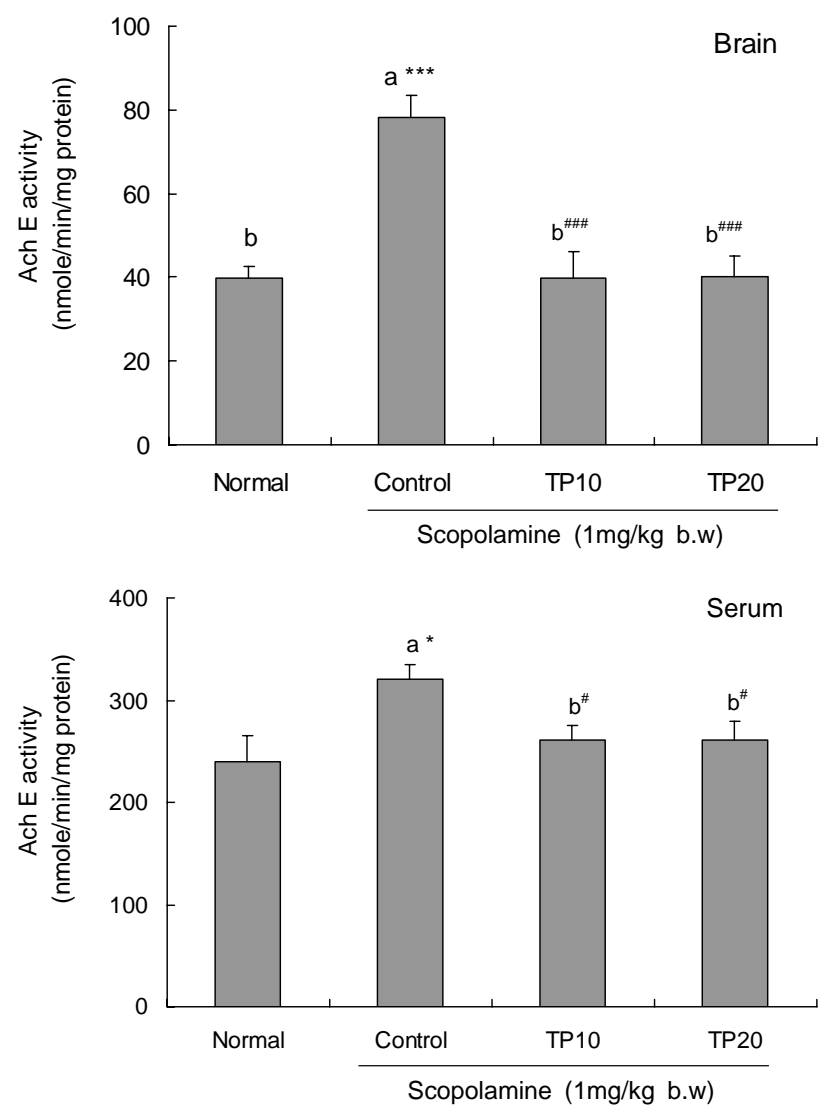

Fig. 3. Effect of TP on AchE activity in the serum and brain. ${ }^{*} \mathrm{p}<0.05$ and ${ }^{* * *} \mathrm{p}<0.001$ vs. normal. ${ }^{\#} \mathrm{p}<0.05$ and ${ }^{\# \#} \mathrm{p}<0.001$ vs. control ( $\mathrm{n}=12$ per group).

\section{ACKNOWLEDGEMENT}

This work was supported by the Buyeo-gun Agricultural Technology Center.

\section{REFERENCES}

1. Beatty WW, Butters N, Janowsky D. 1986. Memory failure after scopolamine treatment: implications for cholinergic hypothesis of dementia. Behav Neural Biol 45: 196-211.

2. Jones GMM, Sahakian BJ, Levy R, Warburton DM, Gray JA. 1992. Effects of acute subcutaneous nicotine on attention, information processing and short-term memory in Alzheimer's disease. Psychopharmacology 108: 485-494.

3. Eidi M, Zarrindast MR, Eidi A, Oryan S, Parivar K. 2003. Effects of histamine and cholinergic systems on memory retention of passive avoidance learning in rats. Eur $J$ Pharmacol 465: 91-96.

4. Dunnett SB, Toniolo G, Fine A, Ryan CN, Björklund A, Iversen SD. 1985. Transplantation of embryonic ventral forebrain neurons to the nucleus basalis magnocellularis: II. Sensorimotor and learning impairments. Neuroscience 16: 787-797.

5. Levy ML, Cummings JL, Kahn-Rose R. 1999. Neuropsychiatric symptoms and cholinergic therapy for Alzheimer's disease. Gerontol 45: 15-22.

6. Musial A, Bajda M, Malawska B. 2007. Recent develop- 
ments in cholinesterases inhibitors for Alzheimer's disease treatment. Curr Med Chem 14: 2654-2679.

7. Zhong CB, Pan YP, Tong XY, Xu XH, Wang XL. 2005. Delayed rectifier potassium currents and Kv2.1 mRNA increase in hippocampal neurons of scopolamine-induced memory-deficient rats. Neurosci Lett 373: 99-104.

8. Ebert U, Kirch W. 1998. Scopolamine model of dementia: electroencephalogram findings and cognitive performance. Eur J Clin Invest 28: 944-949.

9. Collerton D. 1986. Cholinergic function and intellectual decline in Alzheimer's disease. Neuroscience 19: 1-28.

10. Heber D, Lu QY. 2002. Overview of mechanisma of action of lycopene. Exp Bio Med 227: 920-923.

11. Rao AV, Agarwal S. 2000. Role of antioxidant lycopene in cancer and heart disease. J Am Coll Nutr 19: 563-569.

12. Bhuvaneswari V, Nagini S. 2005. Lycopene: a review of its potential as an anticancer agent. Curr Med Chem Anticancer Agents 5: 627-635.

13. Rao AV, Ray MR, Rao LG. 2006. Lycopene. Adv Food Nutr Res 51: 99-164.

14. George B, Kaur C, Khurdiya DS, Kapoor HC. 2004. Antioxidant in tomato (Lycopene esculentum) as a function of genotype. Food Chem 84: 45-51.

15. Morris RG. 1984. Development of water maze procedure for studying spatial learning in the rat. J Neurosci Methods 11: 47-60.

16. Ellman GL, Courtney KD, Andres VJ, Featherstone RM. 1961. A new and rapid colormetric determination of acetylcholinesterase activity. Biochem Pharmacol 7: 88-95.

17. Lowry OH, Rosebrough NJ, Farr AL, Randall RJ. 1993. Protein measurement with Folin phenol reagent. $J$ Biol Chem 193: 265-275.

18. Kim DH, Kim DY, Kim YC, Jung JW, Lee SJ, Yoon BH, Cheong JH, Kim YS, Kang SS, Ko KH, Ryu JH. 2007. Nodakain, a coumarin compound, ameliorates sco- polamine-induced memory disruption in mice. Life Sci 80: 1944-1950.

19. Fan Y, Hu JF, Li J, Yang Z, Xin XL, Wang J, Ding J, Geng MY. 2005. Effect of acidic oligosaccharide sugar chain on scopolamine-induced memory impairment in rats and its related mechanisms. Neurosci Lett 374: 222-226.

20. Levy AI. 1996. Muscarinic acetylcholine receptor expression in memory circus; implications for treatment of Alzheimer disease. Proc Natl Acad Sci 93: 13541-13546.

21. Cutler NR, Stramelk JJ. 2001. Review of the next generation of Alzheimer's disease therapeutics; challenges for drug development. Prog Neuropsychopharmacol Biol Psychiatry 25: 27-57.

22. Ezio G. 1998. Cholinesterase inhibitors for Alzheimer's disease therapy: from tacrines to future applications Neurochem Int 32: 413-419.

23. Siddiqui MF, Levey AI. 1999. Cholinergic therapies in Alzheimer's disease. Drug Future 24: 417-444.

24. Aust O, Sies H, Atahl W, Polidory MC. 2001. Analysis of lipophilic abtioxidants in human serum and tissues: tocopherols and carotenoids. J Chromatogr 936: 83-93.

25. Rao AV, Agarwal S. 1999. Role of lycopene as antioxidant carotenoid in the prevention of chronic disease: a review. Nutr Res 19: 305-323.

26. Clinton SK. 2000. Lycopene: chemistry, biology, and implications for human health and disease. Nutr Rev 56: $35-51$.

27. Emilla AM M, Resina LM, F, Danilo WF, Daniela N, Fabiola S, France B, Emil K. 2005. Effects of diet energy level and tomato powder consumption on antioxidant status in rats. Clin Nutr 24: 1038-1046.

28. Lee SY, Son DH, Ha TY, Hong JT. 2005. Protective effect of sesaminol glucosides on memory impairment and $\beta$, $\gamma$-secretase activity in vivo. Yahhak Hoeji 49: 168-173.

(Received December 9, 2008; Accepted December 11, 2008) 